\title{
Editorial
}

\section{Graduate Nursing Research}

It is an honour to assist students from the first cohort of the Master of Science in Nursing (MScN) program publish their research in a Special Issue of the Rwanda Journal of Medicine and Health Sciences (RJMHS). A total of 111 nurses and midwives graduated in August 2017, and shortly after, the University of Rwanda (UR) hired 24 as assistant lecturers to co-teach in the second cohort with support from HRH senior lecturers.

In December 2017, a few of the HRH lecturers began hosting a series of bi-weekly writing retreats, with support from senior academics and specialists, to help transform the assistant lecturers' dissertations into articles. I am grateful to everyone who made this publication possible. Guest speakers at the writing retreats included Dean Donatilla Mukamana and Dr Darius Gishoma from SoNM; Dean Linda McCreary and Dean Terry Weaver from the University of Illinois, Chicago (UIC); and Theogene Nyandwi from the UR Research Office. Several visiting senior editors from Elsevier provided publishing support: Dr Marc Chahin and Jasmin Bakker presented at the writing retreats, and Dr Constanza Villalba, Dr Daniel Staemmler, and Dr Juliana Trajano presented workshops that were open to all faculty members and students. The Academic Enhancement Centre provided a one-day workshop and individual support with the English language. HRH senior lecturers, Dr Anita Collins and Dr Lakshmi Rajeswaran, provided regular support throughout the seven-month series of retreats. Professor Jean Bosco Gahutu, RJMHS Editor; Professor Mi Ja Kim, Deputy Editor and Dean Emerita of the College of Nursing at UIC; along with other editorial team members provided instrumental RJMHS publishing support. Finally, this publication was made possible through the generous and continued support of our Vice Chancellor, Professor Phil Cotton.

This Special Issue features 14 articles by the UR assistant lecturers as first authors. The topics are based on their research within the eight MScN speciality tracks, namely Critical Care; Education, Leadership, and Management; Medical Surgical; Neonatal; Nephrology; Oncology; Pediatric; and Perioperative. Co-authors of the publications include the research supervisors, and senior lecturers and peers involved in the manuscript development.

The research presented in the Special Issue includes 12 quantitative and two qualitative designs that are aligned with the priority research areas of the SoNM and national health research agenda. Each specialty track is represented at least once. The first six articles address important health issues, such as, adolescent parenting, prevalence and risk factors of birth asphyxia, parental education for preterm infants in the neonatal intensive care unit (NICU), anxiety level of patients awaiting surgery, anxiety and depression among cancer patients, and vasectomy as a means of contribution to family planning. The next six articles assess the nurse's role in patient care, including neonatal pain management; nurse burnout and effect on critical care patients; oral care practice to prevent bacterial infection in ventilated patients; adherence to hand hygiene; health education of Type Two diabetes mellitus; and hemodialysis care. The final two articles assess nursing students' knowledge and preventive practice of chronic kidney disease, and satisfaction levels in the clinical learning environment.

The research goal of the SoNM is to be a globally engaged, innovative, research-driven school. The RJMHS is an ideal resource for SoNM faculty and students to disseminate their findings in an academic, peer-reviewed journal. Expanding statistical support from the SoNM, language support from the Academic Enhancement Centre, and research support via international collaboration could even further enhance faculty and students' participation in research and increase the number of publications. We hope that you enjoy learning about the research of the new junior faculty, which we believe will help build momentum for SoNM research and benefit individuals, families, and communities throughout Rwanda.

Rwanda J Med Health Sci 2019;2(2):85.

\section{Pamela Meharry, PhD, CNM}

Midwifery and Neonatal Educator

Human Resources for Health (HRH)

In partnership with University of Rwanda and University of Illinois, Chicago

Meharry3@uic.edu

Guest Editor 